\title{
ENHANCEMENT BY ANESTHETIC AND CONVULSANT BARBITURATES OF GABA BINDING TO RAT BRAIN SYNAPTOSOMAL MEMBRANES ${ }^{1}$
}

\author{
MAX WILLOW AND GRAHAM A. R. JOHNSTON
}

Department of Pharmacology, John Curtin School of Medical Research, Australian National University, Canberra, Australia and Department of Pharmacology, University of Sydney, Sydney, N.S.W., 2006, Australia

\begin{abstract}
All of the anesthetic (amylobarbitone, butobarbitone, pentobarbitone, phenobarbitone, and secobarbitone) and convulsant (5-ethyl-5-(3'-methylbut-2-enyl) barbituric acid (3M2B) and 5-ethyl-5-(2' cyclohexylidene-ethyl)barbituric acid (CHEB)) barbiturates tested enhanced the binding of GABA to a carefully prepared $P_{2}$ membrane fraction from rat brain in a dose-dependent manner. These findings are in agreement with the potentiation of the inhibitory effects of GABA in many neuronal systems by both classes of barbiturates.
\end{abstract}

Anesthetic barbiturates enhance the actions of $\gamma$-aminobutyric acid (GABA) in a number of in vivo (Eccles et al., 1971; Lodge and Curtis, 1978; Nicoll, 1972; Nicoll et al., 1975) and in vitro preparations of mammalian central nervous tissue (Evans, 1979; Ransom and Barker, 1976; Scholfield, 1977). Attempts to demonstrate an enhancement by such barbiturates of the binding of GABA to various membrane preparations of mammalian brain, however, have been largely unsuccessful (Enna and Snyder, 1976; Olsen et al., 1979; Peck et al., 1976). Recently, Willow and Johnston (1980) described a dose-dependent enhancement by pentobarbitone of GABA binding in crude rat synaptosomal membranes. In the preparation of this membrane fraction, special attention was given toward limiting the amount of chemical and mechanical disruption, procedures often used to maximize GABA binding presumably by removing endogenous inhibitors (Andrews and Johnston, 1979). The enhancement of GABA binding by pentobarbitone is consistent with electrophysiological studies using intact preparations. The present study examines the effects of several anesthetic and convulsant barbiturates on GABA binding in order to determine whether enhancement of GABA binding is a property common to barbiturates in general.

\section{Materials and Methods}

Crude synaptosomal membranes were prepared according to methods described previously (Willow and

\footnotetext{
${ }^{1}$ We would like to thank Eli Lilly and May and Baker for kindly donating samples of the anesthetic barbiturates used in this study. We would also like to express our gratitude to Dr. P. R. Andrews and Dr. H. Downes for kindly donating samples of 5-ethyl-5-(2'-cyclohexylidene-ethyl)barbituric acid and 5-ethyl-5-(3'-methylbut-2-enyl)barbituric acid and to Ms. C. Eggins for her skilled technical assistance during this study.
}

Johnston, 1980). Male Wistar rats (250 to $350 \mathrm{gm}$ ) were decapitated, and the brains were removed quickly and homogenized in ice cold $0.32 \mathrm{M}$ sucrose using a glass homogenizer fitted with a Teflon pestle $(0.22 \mathrm{~mm}$ clearance in diameter). The homogenate $(10 \% \mathrm{w} / \mathrm{v})$ was centrifuged at $1000 \times g_{a v}$ for $10 \mathrm{~min}$ and the resultant nuclear pellet was washed once. The combined supernatant was centrifuged at $14,500 \times g_{u v}$ for $20 \mathrm{~min}$ and the mitochondrial/synaptosomal $\left(\mathrm{P}_{22}\right)$ pellet was washed 8 to 10 times by resuspension in ice cold $50 \mathrm{~mm}$ Tris/citrate buffer (pH 7.1) and centrifuged at $20,000 \times g_{\text {av }}$ for $20 \mathrm{~min}$. GABA binding was studied by incubating the resuspended nembrane material $(0.5 \mathrm{mg}$ of protein in $2 \mathrm{ml}$ of Tris/citrate buffer, pH 7.1) for $5 \mathrm{~min}$ at $4^{\circ} \mathrm{C}$ with $2.3 \mathrm{nM}$ $\left[{ }^{3} \mathrm{H}\right] \mathrm{GABA}(60 \mathrm{Ci} / \mathrm{mmol}$, Radiochemical Centre, Amersham). This was followed by centrifugation for $10 \mathrm{~min}$ at $48,000 \times g_{a v}$, removal of the supernatant, and superficial rinsing of the pellet twice with $5 \mathrm{ml}$ of ice cold distilled water. Nonspecific binding was assessed as that fraction of bound GABA not displaced by $1 \mathrm{~mm}$ unlabeled GABA. Typically, total and nonspecific binding was 3000 and $500 \mathrm{cpm}$, respectively. Studies using density gradient centrifugation showed that specific GABA binding was highest in the synaptosomal fraction $(2600 \mathrm{cpm} / 0.5 \mathrm{mg})$ with only a small amount of binding to mitochondria $(600 \mathrm{cpm} / 0.5 \mathrm{mg})$. Protein was measured according to the method of Lowry et al. (1951). The effects of varying concentrations ( 0 to $800 \mu \mathrm{M}$ ) of barbiturates (sodium salts) on GABA binding were studied by incubating the resuspended membrane material with $2.3 \mathrm{nM}\left[{ }^{3} \mathrm{H}\right] \mathrm{GABA}$ in the presence of the barbiturate for the 5 -min period required to reach equilibrium as described above. The effect of picrotoxinin (10 to $100 \mu \mathrm{M})$ on GABA binding in the presence and absence of barbiturates was studied in a similar manner. 


\section{Results}

All anesthetic barbiturates tested enhanced GABA binding in a dose-dependent manner (Fig. 1). Butobarbitone, secobarbitone, and amylobarbitone were all approximately equipotent, with the threshold concentration at $6.25 \mu \mathrm{M}$. Pentobarbitone was slightly weaker than these compounds and phenobarbitone was 3 to 4 times less potent than pentobarbitone. All of these compounds produced a maximal enhancement of $\left[{ }^{3} \mathrm{H}\right] \mathrm{GABA}$ binding of approximately $40 \%$. Sodium chloride, $100 \mu \mathrm{M}$, had no effect on GABA binding measured under these conditions. The enhancement of GABA binding by pentobarbitone has been shown to result from an increase in the affinity of a high affinity binding site with no change in the density of binding sites (Willow and Johnston, 1980).

The two convulsant barbiturates tested, 5-ethyl-5-(3'methylbut-2-enyl)barbituric acid (3M2B) and 5-ethyl-5(2'-cyclohexylidene-ethyl)barbituric acid (CHEB), also enhanced GABA binding in a similar manner to the anesthetic barbiturates, both being approximately equipotent to butobarbitone, secobarbitone, and amylobarbitone (Fig. 2). Picrotoxinin at low concentrations (10 $\mu \mathrm{M})$ completely abolished the enhancement of GABA binding by amylobarbitone, while higher concentrations $(100 \mu \mathrm{M})$ were required to block completely the enhancement of binding by CHEB (Table I). Picrotoxinin (100 $\mu \mathrm{M})$ alone did not modify GABA binding.

\section{Discussion}

The present study indicates that both anesthetic and convulsant barbiturates enhance $\left[{ }^{3} \mathrm{H}\right] \mathrm{GABA}$ binding to the crude $\mathrm{P}_{2}$ fraction of rat brain. The effective concentrations of anesthetic barbiturates $(6.25$ to $100 \mu \mathrm{M})$ are within the range of concentrations of these substances found in the brains of laboratory animals during surgical anesthesia (Richards, 1972). The greater potency of pentobarbitone when compared with phenobarbitone is also consistent with the relative potencies of these barbiturates in enhancing the actions of GABA on frog motoneurons (Nicoll and Wojtowicz, 1980) and in prolonging the inhibitory postsynaptic potential recorded in guinea pig olfactory cortex slices in vitro (Scholfield, 1977). The enhancement of GABA binding by the two convulsant barbiturates, CHEB and $3 \mathrm{M} 2 \mathrm{~B}$, is in agreement with the finding that $3 \mathrm{M} 2 \mathrm{~B}$, like pentobarbitone, enhanced the inhibitory effect of GABA on cat spinal interneurons (Lodge, 1979). Nicoll (1975) also has shown that CHEB depolarizes primary afferent fibers in the isolated frog spinal cord in a similar GABA-mimetic fashion to pentobarbitone.

The finding that picrotoxinin abolished the enhancement of GABA binding by amylobarbitone and CHEB, without altering binding in the absence of barbiturates, suggests that the site of enhancement may be at a picrotoxinin-sensitive ionophore rather than a picrotoxinin-

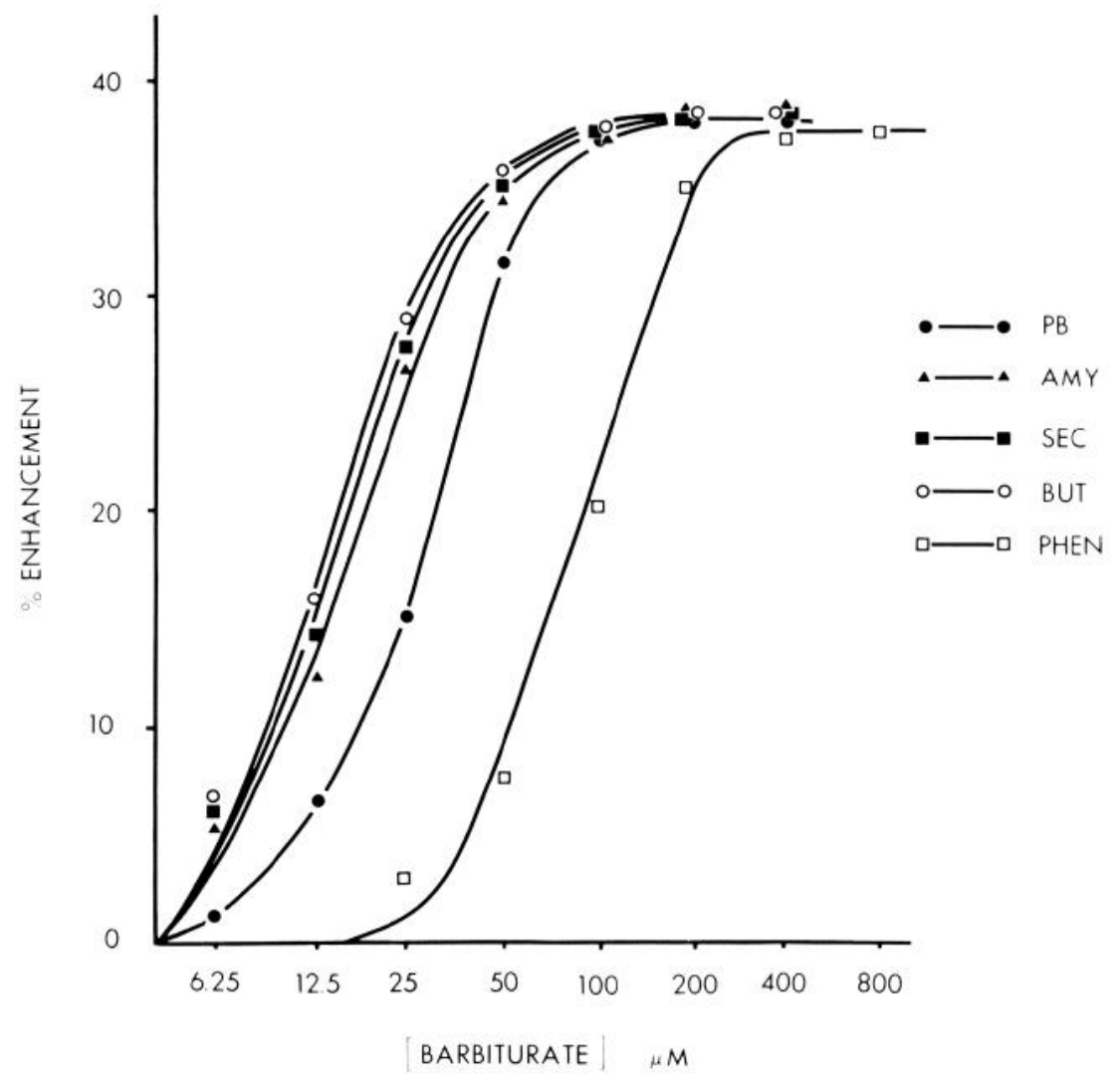

Figure 1. Effect of pentobarbitone $(P B)$, amylobarbitone $(A M Y)$, secobarbitone $(S E C)$, butobarbitone $(B U T)$, and phenobarbitone $(P H E N)$ on GABA binding in crude synaptosomal $\left(\mathrm{P}_{2}\right)$ membranes. Each point represents the mean of six experiments. The standard error of the mean, omitted for clarity, did not exceed $7 \%$. 


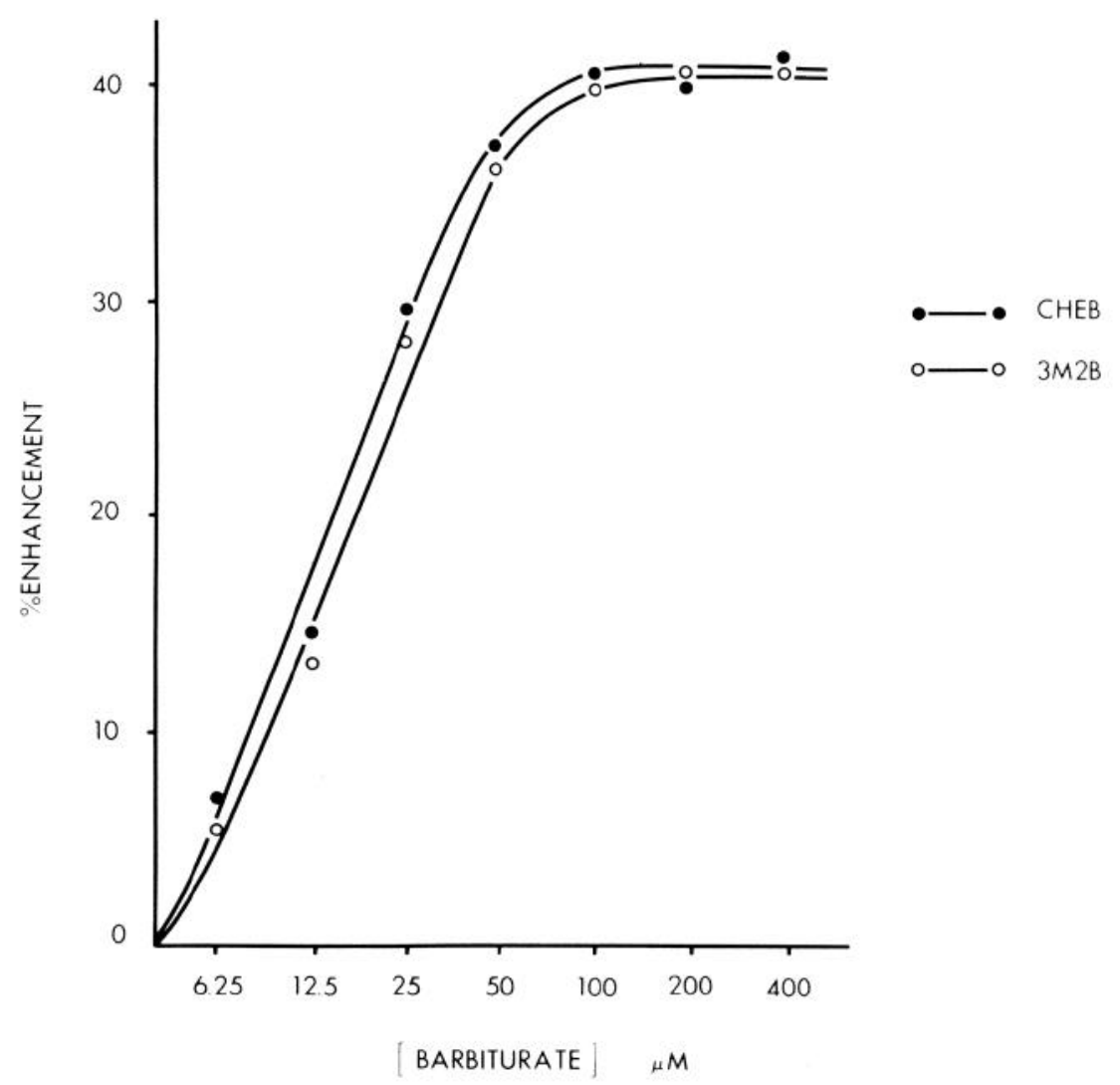

Figure 2. Effect of CHEB and 3M2B on GABA binding in crude synaptosomal $\left(\mathrm{P}_{2}\right)$ membranes.

TABLE I

Effect of picrotoxinin on the enhancement of GABA binding by anesthetic and convulsant barbiturates

\begin{tabular}{lc}
\hline \multicolumn{1}{c}{ Drug $(\mu \mathrm{M})$} & \multicolumn{1}{c}{ Response } \\
\hline & \% of control \pm SEM \\
Control & $100 \pm 4.5(6)^{a}$ \\
Picrotoxinin (100) & $103 \pm 2.4(6)$ \\
Amylobarbitone (100) & $130 \pm 2.3(6)^{b}$ \\
Amylobarbitone (100) + picrotoxinin (10) & $104 \pm 4.3(6)$ \\
CHEB (100) & $131 \pm 7.2(6)^{c}$ \\
CHEB (100) + picrotoxinin (10) & $130 \pm 1.7(6)^{b}$ \\
CHEB (100) + picrotoxinin (50) & $118 \pm 7.3(6)$ \\
CHEB (100) + picrotoxinin (100) & $101 \pm 6.0(6)$
\end{tabular}

${ }^{a}$ The number of observations are denoted in parentheses.

${ }^{b}$ Significantly different from control values at $p<0.001$ by the Student's $t$ test.

${ }^{c}$ Significantly different from control values at $p<0.01$ by the Student's $t$ test.

insensitive GABA receptor (Andrews and Johnston, 1979). This is in agreement with the observation that barbiturates antagonize the binding of dihydropicrotoxinin to fresh rat cortical $\mathrm{P}_{2}-\mathrm{P}_{3}$ membranes (Ticku and Olsen, 1978). While our techniques prevent us from establishing whether the barbiturate enhancement of GABA binding is bicuculline sensitive (since bicuculline antagonizes binding in the absence of barbiturates), it has been shown that pentobarbitone does not influence (+)-bicuculline-methiodide binding to rat cerebellar synaptic membranes (Möhler and Okada, 1977). In addition picrotoxinin, but not bicuculline, abolishes the enhancement of GABA-mediated hyperpolarization of frog motoneurons by pentobarbitone (Nicoll and Wojtowicz, 1980). The present study showed that a higher concentration of picrotoxinin $(100 \mu \mathrm{M})$ was required to block completely the CHEB-mediated enhancement of GABA binding compared to the concentration required to abolish the enhancement seen with amylobarbitone. Consistent with this finding that anesthetic and convulsant barbiturates may differ in their affinity for the picrotoxinin binding site is the observation that convulsant barbiturates are more potent than anesthetic barbiturates in displacing $\left[{ }^{3} \mathrm{H}\right]$ dihydropicrotoxinin in rat brain $\mathrm{P}_{2}-\mathrm{P}_{3}$ membranes (Ticku and Olsen, 1978).

The present findings are in agreement with the observation that anesthetic barbiturates enhance the actions of GABA in the vertebrate central nervous system, a factor which may be of importance to their action as anesthetics. On the other hand, convulsant barbiturates also enhance GABA binding and such an effect seems unlikely to contribute to the convulsant action of these compounds, particularly as $3 \mathrm{M} 2 \mathrm{~B}$, like bicuculline and picrotoxinin, reduces GABA-mediated primary afferent depolarization (Lodge, 1979). The effects of convulsant barbiturates on the release of inhibitory and excitatory transmitters at certain synapses may be more important factors in determining their pharmacological actions (Nicoll, 1978), particularly since convulsant and anesthetic barbiturates have differential effects on amino acid release (Willow et al., 1980). 


\section{References}

Andrews, P. R., and G. A. R. Johnston (1979) GABA agonists and antagonists. Biochem. Pharmacol. 28: 2697-2702.

Eccles, J. C., D. S. Faber, and H. Taborikova (1971) The action of a parallel fiber volley on the antidromic invasion of Purkinje cells of cat cerebellum. Brain Res. 25: 335-356.

Enna, S. J., and S. H. Snyder (1976) A simple, sensitive and specific radioreceptor assay for endogenous GABA in brain tissue. J. Neurochem. 26: 221-224.

Evans, R. H. (1979) Potentiation of the effects of GABA by pentobarbitone. Brain Res. 171: 113-120.

Lodge, D. (1979) Effect of a convulsant barbiturate on the inhibitory action of GABA in the cat spinal cord. Clin. Fxp. Pharmacol. Physiol. 6: 686.

Lodge, D., and D. R. Curtis (1978) Time course of GABA and glycine actions on cat spinal neurones: Effect of pentobarbitone. Neurosci. Lett. 8: 125-129.

Lowry, O. H., N. J. Rosebrough, A. L. Farr, and R. J. Randall (1951) Protein measurement with the Folin phenol reagent. J. Biol. Chem. 193: 265-275.

Mohler, H., and T. Okada (1977) GABA receptor binding with ${ }^{3} \mathrm{H}$ (+)bicuculline-methiodide in rat CNS. Nature 267: 65-67.

Nicoll, R. A. (1972) The effects of anaesthetics on synaptic excitation and inhibition in the olfactory bulb. J. Physiol. (Lond.) 223: 803-814.

Nicoll, R. A. (1975) Presynaptic action of barbiturates in the frog spinal cord. Proc. Natl. Acad. Sci. U. S. A. 72: 1460-1463.

Nicoll, R. A. (1978) Sedative-hypnotics: Animal pharmacology. In Handbook of Psychopharmacology, L. L. Iversen, S. D. Iversen, and S. H. Snyder, eds., Vol. 12, pp. 187-234, Plenum Press, New York.
Nicoll, R. A., and J. M. Wojtowicz (1980) The effects of pentobarbital and related compounds on frog motoneurons. Brain Res. 191: 225-237.

Nicoll, R. A., J. C. Eccles, T. Oshima, and F. Rubia (1975) Prolongation of hippocampal inhibitory postsynaptic potentials by barbiturates. Nature 258: 625-627.

Olsen, R. W., M. K. 'Iicku, D. Greenlee, and P. Van Ness (1979) GABA receptor and ionophore binding sites: Interactions

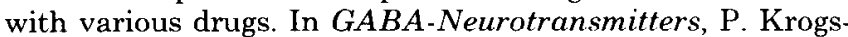
gaard-Larsen, J. Scheel-Krüger, and H. Kofod, eds., pp. 165178, Munksgaard, Copenhagen.

Peck, E. J., A. L. Miller, and B. R. Lester (1976) Pentobarbital and synaptic high-affinity receptive sites for gamma-aminobutyric acid. Brain Res. Bull. 1: 595-597.

Ransom, B. R., and J. L. Barker (1976) Pentobarbital selectively enhances GABA-mediated post-synaptic inhibition in tissue cultured mouse spinal neurones. Brain Res. 114: 530-535.

Richards, C. D. (1972) On the mechanism of barbiturate anaesthesia. J. Physiol. (Lond.) 227: 749-767.

Scholfield, C. N. (1977) Prolongation of post-synaptic inhibition by barbiturates. Br. J. Pharmacol. 59: 507P.

Ticku, M. J., and R. W. Olsen (1978) Interaction of barbiturates with dihydropicrotoxinin binding sites related to the GABA receptor-ionophore system. Life Sci. 22: 1643-1652.

Willow, M., and G. A. R. Johnston (1980) Enhancement of GABA binding by pentobarbitone. Neurosci. Lett. 18: 323327.

Willow, M., J. C. Bornstein, and G. A. R. Johnston (1980) The effects of anaesthetic and convulsant barbiturates on the efflux of $\left[{ }^{3} \mathrm{H}\right]-\mathrm{D}$-aspartate from brain minislices. Neurosci. Lett. 18: 185-190. 